\title{
An Exercise in Happiness: Physical Activity Choices and Psychological Wellbeing in Post-Partum Mothers
}

\section{Gemma L Witcomb* and Zoe Harding}

\author{
School of Sport, Exercise, and Health Sciences, Loughborough University, Loughborough, UK
}

\begin{abstract}
Depression in the post-partum period affects a substantial number of mothers and can have serious consequences for quality of life and parenting. It is therefore imperative that the factors that can protect against and provide resilience to parental depression are identified. Exercise and physical activity has previously been found to be effective in decreasing symptoms of depression however the efficacy of exercise as an intervention is still unclear. Using a cross-sectional design and an opportunistic sample, this study sought to explore what exercise mothers choose to, or are able to, engage in and associations with depression and social support. Three-hundred and four mothers (mean age $=32.7$ years) with young children (mean age $=14.2$ months) completed an online questionnaire consisting of the Edinburgh Postnatal Depression Scale (EPNDS), Multidimensional Scale of Perceived Social Support (MSPSS) and questions on their physical activity choices (what type, how often, etc). Mothers were divided into groups based on their self-reported exercise habits: No exercise (N-E), own exercise (O-E) and mother-baby exercise classes (M-B). The results found that mothers who engaged in mother-baby exercise classes had significantly less depression symptomology. Frequency of attending classes was associated with social support, with higher scores on the measure of depression related to lower levels of social support (in total and separately from family, friends, and significant others). Not participating in any exercise was reported to be related to lack of childcare and time. These results suggest that, outside of targeted interventions, mother who seek out group exercise classes gain in social support, which may be protective against depression. Assisting mothers with opportunities to engage with such classes should be a priority.
\end{abstract}

Keywords

Depression, Exercise, Physical activity, Postnatal, Post-partum, Social support

\section{Introduction}

The transition to parenthood is a major life event $[1,2]$. For many, becoming a parent is a difficult, yet welcomed and joyous time. However, for some, the associated physical, physiological, psychological and social changes that accompany the transition to parenthood can lead to mental health problems $[3,4]$. Not only are hormonal factors implicated in the development of problems [5] but also factors related to changes in body image, both during [6] and after [7] childbirth. Indeed, preoccupation with body image has been shown to be such an important variable that it can influence decisions to breastfeed [8]. Modern parenthood has also been described as an incredibly isolating experience [9], particularly for single parents, those in the workforce, and those who are, geographically, not in close proximity to sources of support [9].

Postnatal depression (PND) is a life-threatening and debilitating clinical depression that occurs during the first year after childbirth [10]. PND is estimated to affect around $13 \%$ of new mothers (WHO, 2015). However, PND does not just affect women, with a recent estimate from Ireland estimating a prevalence of $12 \%$ in fathers [11]. The similarity in prevalence rates may reflect the fact that PND in one parent permeates the family relationships and can affect everyone. Indeed, while PND is as common as other forms of depression in the general population, it is of great concern since it fundamentally

*Corresponding author: Dr. Gemma L Witcomb, PhD, School of Sport, Exercise, and Health Sciences, Loughborough University, Loughborough, LE11 3TU, United Kingdom, Tel: +44-1509-223084; Fax: +44-(0)1509-22630

Accepted: October 25, 2018: Published online: October 27, 2018

Citation: Witcomb GL, Harding Z (2018) An Exercise in Happiness: Physical Activity Choices and Psychological Wellbeing in Post-Partum Mothers. Arch Sports Med 2(2):109-115

Copyright: (c) 2018 Witcomb GL, et al. This is an open-access article distributed under the terms of the Creative Commons Attribution License, which permits unrestricted use, distribution, and reproduction in any medium, provided the original author and source are credited. 
Citation: Witcomb GL, Harding Z (2018) An Exercise in Happiness: Physical Activity Choices and Psychological Wellbeing in Post-Partum Mothers. Arch Sports Med 2(2):109-115

affects a parents' ability to engage in parenting. Sufferers are typically disengaged and hostile towards their children [12], for example engaging in less play, but also may be unable to pay due regard to safety procedures [13]. As a result, parental PND is associated with a number of negative outcomes on child health and behaviour. A recent longitudinal study found that PND doubled the risk of a child developing behavior disturbances and if the PND persisted past one year it was also associated with lower educational attainment and the development of depression in the child [14]. Treatment of PND can involve both therapeutic and pharmacological treatments. However, accessing these requires a disclosure that a person is suffering and many mothers are often reluctant to report depressive symptoms $[1,15]$. Behavioural interventions such as Cognitive Behavioural Therapy (CBT) and Interpersonal Therapy (IPT) [16-18] are common, but the active involvement required during treatment is not always feasible for depressed mothers who, by definition, find it hard to engage and are likely to be stretched for time and childcare assistance [19]. Alternative pharmacological therapies are not always appropriate for post-partum mothers, particularly those who wish to breastfeed, as antidepressant compounds may be passed onto the infant via breast milk [20]. Consequently, it seems logical to promote prevention against the onset of depression rather than relying on these treatments [21]. The most effective preventative combination is currently unknown, with data on the effectiveness of drug treatment inconclusive [22]. Therefore, further investigation is needed to facilitate improvements in the rates of PND [23].

Two factors that have been identified in the general population as protecting against the risk of depression are 1) Social support and 2) Exercise. For new mothers, attending mother-baby groups can help to bolster social support through new connections and friendships $[24,25]$. These groups help to develop a varied network of support, specific to parenting [25], which subsequently enhances resilience against PND $[1,26]$. As such, group activities are being built into preventative measures as more popular types of intervention [27,28]. Similarly, exercise has been shown to have benefits in reducing depression in the general population [29-31] and has been shown to promote positivity of outlook and wellbeing in post-partum women [32]. However, while exercise interventions provide promise, particularly as post-partum mother's physical activity levels are currently below-recommended guidelines [33], mothers may face difficulties implementing and sustaining new or previously established activity routines due to novel barriers that arise in motherhood [34,35], such as child care and limited time [36]. However, exercise activities that are tailored to mothers to attend with their children may be an efficient way of overcoming these barriers [37] and limited evidence suggests that such classes may also be associated with greater benefits to wellbeing [38], most likely due to the additive effects of the social support $[24,39,40]$.

Previous research has attempted to explore the effectiveness of exercise versus other interventions (e.g., educational support) using randomly controlled designs and a number of reviews have assessed and evaluated these $[41,42]$, concluding that postnatal exercise has both physiological and psychological benefits, particularly if there is an added element of social support, which may benefit through the structure gained from organised classes. However, these studies often involve participants who are at risk for PND or have been diagnosed with PND, and therefore may be biased towards samples that already have an awareness of mental health issues. These studies often also involve prescribing tailored exercise programs and are therefore not always representative of what a mother might have access to in real-life [43]. Therefore, the novelty of this cross-sectional study is to explore how mothers' free-choice engagement in exercise (mother-baby class, own exercise, or no exercise), influenced by real-world factors such as personal preference, logistics, and availability, is associated with depression symptomology and perceived social support in a representative sample of post-partum mothers. This will provide increased translational understanding of the effectiveness of exercise and/or classes, when taken in the context of additional barriers. Thus this study sought to test the hypothesis that mothers who engage in exercise will have less depressive symptomology that mothers who do not, and that those who engage in mother-baby classes specifically will have the least depressive symptomology and greater social support.

\section{Methods}

\section{Participants}

Mothers with children aged 0-3 years-old were recruited using opportunistic and snowball sampling techniques. The study was advertised via children's centres, playgroups, online forums, and social networking sites. The questions regarding exercise and social support were part of a larger study investigating mental wellbeing and parenting.

\section{Measures}

Bristol Online Survey was used to develop and deliver an online survey consisting of the following measures:

Demographics: Mothers were asked to report their age, ethnicity, marital status, highest level of education, current employment status, how many children were living in their house and the age of their youngest child. 
Citation: Witcomb GL, Harding Z (2018) An Exercise in Happiness: Physical Activity Choices and Psychological Wellbeing in Post-Partum Mothers. Arch Sports Med 2(2):109-115

Physical activity and exercise: Mothers were asked to report their physical activity by responding to the question: "In the past week how many days have you done a total of 30 minutes or more physical activity, which was enough to increase your breathing rate?" with a scale (07) to indicate the number of days. This could include any type of activity. Subsequently, they were asked what type of structured exercise they did (e.g., Mother-baby classes, non-specified exercise classes or own exercise) and how often, with a scale (0-7) to indicate weekly participation. This was followed by a series of questions that asked why they chose to engage in the type of exercise that they do and what barriers they perceive, if any.

Edinburgh Postnatal Depression Scale [44]: This questionnaire is designed specifically for mothers who have recently had a child. It consists of a 10 -item questionnaire asking mothers how they have felt in the past 7 days (e.g." "I have been able to laugh and see the funny side of things"). Participants are asked to answer on a 4-point scale (anchored from "As much as I always could" to "Not at all"). Questions are scored from 0-3 (or 3-0 if reversed scored), with a maximum possible score for the scale being 30 . A score of 10-13 is indicative of possible depression and a score of 13 and above indicates likely depression. The Cronbach's alpha for this measure was 0.89 , suggesting good internal reliability $(\alpha>0.8)$.

Multidimensional Scale of Perceived Social Support [45]: This scale measuressocial support from friends, family and significant others. It consists of a 12 item questionnaire, divided equally into 3 subscales: Family (e.g., "My family really tries to help me"), friends (e.g., "I can count on my friends when things go wrong"), and significant other items (e.g., "There is a special person around when I am in need"). Mothers were asked to indicate their agreement with the statements on a 7-point scale from $1=$ Very Strongly Disagree to $7=$ Very Strongly Agree. The total score is calculated as the mean of the 12 scores and the subscale total scores are the means of the scores for the 4 questions related to the subscale. Mean scores ranging from 1-2.9 indicate low support, a score of 3-5 indicates moderate support and a score of 5.1-7 indicates high support. Cronbach's alpha scores were 0.93 for the overall total score, 0.93 for the family subscale, 0.95 for the friends subscale and 0.95 for the significant other subscale; all showing excellent internal reliability $(a>0.9)$.

\section{Procedure}

Approval was granted by the Loughborough University Ethics Approvals (Human Participants) Sub-Committee for this study. Following this, parenting organisations (e.g., playgroups, online parenting groups) were contacted and asked if they would advertise a survey on parenting behaviours. The data reported here are part of a larger survey on parenting and so mothers were not explicitly recruited to a study on exercise and mental wellbeing. Mothers who saw the advertisements, if interested, could follow the advertised URL to the online survey, where they could first read the Participant Information Sheet. If they were happy to take part, they had to indicate their consent at which point the survey launched and participants completed it at their leisure. If they indicated that they did not consent, the online survey routed to a debrief page that gave the investigator's contact details and sources of support (e.g., health services, Samaritans).

\section{Data analysis}

Data were analysed using IBM SPSS Statistics 24 (IBM Corporation, Armonk, NY, USA). Data were reverse scored where necessary and total and subscale scores were calculated for each of the variables measured. Data did not severely violate assumptions of normal distribution and so differences between groups were analysed using one-way ANOVA, with Tukey post-hoc tests where appropriate. Pearson's correlations were used to assess associations between variables. Significance was set at 0.05 .

\section{Results}

\section{Participants}

A total of 315 mothers completed the survey. Of these, eleven had children over the age of 3 -years and so were excluded from further analysis, leaving a final sample of 304 . The sample was majority White British (93.4\%), married $(68.9 \%)$ or cohabiting (18.1\%), with an education level of undergraduate degree $(41 \%)$. The participants were divided into groups based on their reported exercise habits; $67.4 \%(\mathrm{n}=205)$ were non-exercisers $(N-E), 19.1 \%(n=58)$ were engaging in exercise on their own $(\mathrm{O}-\mathrm{E})$ and $13.5 \%(\mathrm{n}=41)$ were attending mother and baby exercise classes (M-B). The mean age of the mothers was 32.69 years $(S D=5.20)$ and there was no significant difference in the age of the mothers in each of the exercise groups $(F[2,301]=1.416, p=0.244)$. Mothers had been asked to indicate the age of their youngest child, the mean of which was 14.2 months (SD $=8.84)$. The mean age of infants differed between groups $(F[2,301]=5.05, p=0.007)$ with the M-B group having significantly younger children (mean age $=10.6$ months, $S D=8.38$ ) than both the O-E (mean age $=16.3$ months, $S D=8.77)$ and N-E (mean $=14.4, S D=8.78)$ groups. Fifty-three percent of the total sample had only one child and the mean number of children living at home was the same $(\mathrm{n}<2)$ in all exercise group $(F[2,300]=0.99, p=$ 0.906). See Table 1. 
Citation: Witcomb GL, Harding Z (2018) An Exercise in Happiness: Physical Activity Choices and Psychological Wellbeing in Post-Partum Mothers. Arch Sports Med 2(2):109-115

\section{Frequency of exercise}

Mothers were asked to indicate on how many times in the past week they had engaged in physical activity for at least 30 minutes that left them out of breath. Analysis of these responses found no significant differences between the groups $(F[2,301]=0.77, p=0.465)$ with all groups averaging around three. Mothers were also asked to indicate how many times they had attended a structured class in the last week (either mother-baby or own exercise). Analysis of these responses revealed that $\mathrm{O}-\mathrm{E}$ was engaged in significantly more frequently (mean $=1.10$, $S D=0.95)$ than $\mathrm{M}-\mathrm{B}$ classes $($ mean $=0.49, S D=1.08$; $F[1,97]=0.002, p=0.961)$. See Table 1 .

\section{Depression and exercise group}

Depression scores were compared across the three exercise groups; mother-baby (M-B), own exercise (OE) and no exercise $(\mathrm{N}-\mathrm{O})$ by ANOVA. This revealed that there was a significant difference between the groups $(F[2,301]=4.24, p=0.015)$. Post-hoc tests confirmed that the M-B group scored significantly lower on the measure of depression (mean $=7.34, S D=3.46$ ) than both the O-E (mean $=9.43, S D=4.12)$ and N-E (mean $=9.44$, $S D=4.78)$ groups. The latter two did not differ significantly from each other. See Table 2.

\section{Social support and exercise group}

Perceived social support was also compared across the three groups. The ANOVA revealed a significant difference in total scores $(F[2,302]=4.18, p=0.016)$. Posthoc tests confirmed that the O-E group had significantly less social support (mean $=5.26, S D=1.24$ ) than the $\mathrm{M}-\mathrm{B}$ group (mean $=5.86, S D=0.78$ ) and the $\mathrm{N}$-E group (mean $=5.60, S D=1.10$ ). When looking at the subscales separately, there were no significant differences between groups in support from friends and significant others. However, there was a significant difference in support from family $(F[2,303]=6.63, p=0.002)$, with the O-E group having significantly less support from family (mean $=4.79, S D=$ 1.66 ) than the M-B group (mean $=5.56, S D=1.19)$ and the N-E group $($ mean $=5.52, S D=1.35)$. See Table 2 .

\section{Associations between time spent exercising, de- pression and social support}

Pearson's correlations were run to assess the relationship between time spent exercising, depression and social support. Depression was not significantly correlated with frequency of exercising as assessed by attendance at a class (either M-B or O-E; $r=0.005, p=0.926$ ) or any physical activity over 30 minutes $(r=-0.78, p=0.176)$.

Table 1: Mean (SD) demographic information and time spent exercising in each exercise group.

\begin{tabular}{|c|c|c|c|c|c|}
\hline & N-E & O-E & M-B & $F$ & $p$ \\
\hline & $(n=205)$ & $(n=58)$ & $(n=41)$ & & \\
\hline Age (years) & $32.39(5.17)$ & $33.69(5.56)$ & $32.78(4.75)$ & 1.416 & 0.244 \\
\hline No. of children & $1.55(0.67)$ & $1.55(0.65)$ & $1.50(0.75)$ & 0.99 & 0.906 \\
\hline Age of youngest child & $14.4(8.78)$ & $16.26(8.77)$ & $10.66(8.38)$ & 5.05 & 0.007 \\
\hline Times engaged in activity $<30$ mins (days/week) & $2.60(1.93)$ & $2.90(1.78)$ & $2.88(1.98)$ & 0.77 & 0.465 \\
\hline Times attended class (days/week) & - & $1.10(0.95)$ & $0.49(1.08)$ & 0.002 & 0.961 \\
\hline
\end{tabular}

Table 2: Mean (SD) scores on measure of depression (EPNDS) and social support (MSPSS) in each exercise group.

\begin{tabular}{|c|c|c|c|c|c|c|}
\hline & & N-E & O-E & M-B & $F$ & $p$ \\
\hline & & $(n=205)$ & $(n=58)$ & $(n=41)$ & & \\
\hline EPNDS Depression & & $9.44(4.78)^{*}$ & $9.43(4.12)^{* *}$ & $7.34(3.46)^{*, * \star}$ & 4.24 & 0.015 \\
\hline \multicolumn{7}{|l|}{ MSPSS } \\
\hline & Total & $5.60(1.10)^{*}$ & $5.26(1.24)^{*, * *}$ & $5.86(0.78)^{\star *}$ & 4.18 & 0.016 \\
\hline & Family & $5.52(1.35)^{*}$ & $4.79(1.66)^{*,, * *}$ & $5.56(1.19)^{\star \star}$ & 6.63 & 0.002 \\
\hline & Friends & $5.44(1.36)$ & $5.20(1.61)$ & $5.78(0.86)$ & 2.189 & 0.114 \\
\hline & Significant others & $5.99(1.21)$ & $5.80(1.34)$ & $6.24(1.08)$ & 1.587 & 0.206 \\
\hline
\end{tabular}

${ }^{*} \&{ }^{* *}$ denote significant Tukey post hoc differences.

Table 3: Pearson's correlation between depression (EPNDS) and social support (MSPSS) in each exercise group.

\begin{tabular}{|c|c|c|c|c|c|c|}
\hline & \multicolumn{2}{|l|}{ N-E } & \multicolumn{2}{|l|}{ O-E } & \multicolumn{2}{|l|}{ M-B } \\
\hline & \multicolumn{2}{|c|}{$(n=205)$} & \multicolumn{2}{|c|}{$(n=58)$} & \multicolumn{2}{|c|}{$(n=41)$} \\
\hline & $r$ & $p$ & $r$ & $p$ & $r$ & $p$ \\
\hline & \multicolumn{6}{|c|}{ EPNDS Depression } \\
\hline \multicolumn{7}{|l|}{ MSPSS } \\
\hline Total & -0.554 & 0.000 & -0.330 & 0.011 & -0.353 & 0.024 \\
\hline Family & -0.510 & 0.000 & -0.380 & 0.003 & -0.287 & 0.069 \\
\hline Friends & -0.474 & 0.000 & -0.341 & 0.009 & -0.098 & 0.541 \\
\hline Significant others & -0.399 & 0.000 & -0.41 & 0.758 & -0.369 & 0.018 \\
\hline
\end{tabular}


Citation: Witcomb GL, Harding Z (2018) An Exercise in Happiness: Physical Activity Choices and Psychological Wellbeing in Post-Partum Mothers. Arch Sports Med 2(2):109-115

Depression was significantly negatively correlated with all measures of social support; global $(r=-0.492, p<$ $0.001)$, family $(r=0.450, p<0.001)$, friends $(r=-0.423$, $p<0.001)$ and significant others $(r=-0.331, p<0.001)$. Only the MB-group showed no significant correlation between depression and support from friends $(r=-0.98$, $p=0.541)$ and, in this group, frequency of attendance at M-B classes was significantly positively associated with social support from friends $(r=0.331, p=0.037)$. See Table 3.

\section{Reason for exercising and barriers}

The frequency with which mothers were in agreement with different reasons for exercising was explored. For those who engaged in M-B exercise classes $(n=41)$ the main reasons $(>33 \%)$ were to feel good $(n=21 ; 51.2 \%)$, and to meet others $(n=20 ; 48.8 \%)$, and for mental health $(\mathrm{n}=12 ; 29.3)$. In the O-E group $(\mathrm{n}=58)$, the main reasons were to lose weight $(\mathrm{n}=29 ; 50.0 \%)$, feel good ( $\mathrm{n}$ $=29 ; 50.0 \%)$, for mental health $(\mathrm{n}=25 ; 43 \%)$ and to clear the $\operatorname{mind} /$ de-stress $(n=21 ; 36 \%)$. Chi-square tests were used to explore whether there were differences between the $\mathrm{M}-\mathrm{B}$ and $\mathrm{O}-\mathrm{E}$ group in the reasons they engaged in exercise. The analysis showed that there were significant differences in two reasons; to lose weight $\left(X^{2}[1]=6.14\right.$, $p=0.022)$ and to meet people $\left(X^{2}[1]=18.32, p<0.001\right)$. Specially, the O-E group more frequently cited losing weight as a reason compared to the $M-B$ group $(n=30$, $51.7 \%$ vs. $\mathrm{n}=11,26.8 \%$ ), while the M-B group more frequently cited to meet people $(n=20,28.8 \%$ vs. $6,10.3 \%)$ than the O-E group.

In terms of barriers to exercise, those who engaged in no exercise $(\mathrm{n}=205)$ reported barriers mainly in terms of childcare $(\mathrm{n}=98 ; 47.8 \%)$, time $(\mathrm{n}=89 ; 43.4 \%)$ and costs $(n=53 ; 25.8 \%)$.

\section{Discussion}

The aim of the present study was to investigate what type of post-partum exercise mothers spontaneously engage in and associated benefits to mental wellbeing and social support. The study found that most mothers did not engage in any structured exercise. Mothers who engaged in mother-and-baby classes had significantly lower scores on a measure of depression compared to mothers who engaged in their own exercise, or none at all. This is consistent with findings from other studies [40]. The latter two groups had mean scores that were borderline for possible depression [45]. This suggests that engaging in own exercise has no greater benefits for mental wellbeing that not engaging in exercise.

One reason for this may be related to the concurrent social support that is gained from mother-baby exercise classes [46] and aspects of group dynamics [35]. Indeed, in this study, those who engaged in mother-baby classes cited "to meet people" as a major reason for attending, after "to feel good". However, in the own-exercise group the main reason was to lose weight, as well as a number of reasons related to wellbeing. This may be important, since exercise for appearance-related reasons has been found to be associated with less psychological benefits [47]. Thus, although exercise is a valuable tool to combat low mood [48] it may need to occur in conjunction with social support, and be unrelated to appearance, if it is to be effective in this population. This addresses two important aspects of being a mother: the unique transition and social impact of becoming a parent and body image concerns $[49,50]$. Indeed, the only significant association with time spent exercising was for the measure of social support from friends, and only in the mother-baby exercise group. Thus, more frequent engagement in these classes is associated with greater support, and those who attend such classes had lower depression. Since variety of types of support has previously been cited as important [26], such classes may facilitate widening of networks.

This poses an important problem for mothers who may be short on time and resources. Indeed, the main barriers to exercising were cited as lack of childcare and lack of time. In this regard, social support can play a key role in facilitating exercise to occur. This study found that those who engaged in their own exercise reported significantly less social support, and particularly from family, than the other groups, which may be influencing their ability to engage with others. As such, there is a need to consider how parents can be better supported to have the opportunities to engage in physical activity. While mother-baby classes are excellent if a parent has only one child (the infant), they may preclude mothers from attending who have additional children that require care. Thus the translational and clinical implications of this study point to better interventions to support the wider contextual structures that may hinder participation in exercise.

Overall, greater depression was associated with less social support from family, friends, and significant others. This is in line with previous research in many areas that shows that social support is a protective factor against the development of mental health problems $[51,52]$. This was most apparent in the no-exercise group who may be lacking the social support to be able to exercise, and the support and mental health benefits gained from being part of a structured exercise group.

This study was a cross-sectional study and so causal relationship can not be inferred. Indeed, it is possible that those who engage in mother-baby classes had better wellbeing in general. However, the results are consistent with previous studies and the additional strength of this 
Citation: Witcomb GL, Harding Z (2018) An Exercise in Happiness: Physical Activity Choices and Psychological Wellbeing in Post-Partum Mothers. Arch Sports Med 2(2):109-115

study is in the observation of mothers engaging in physical activity without prior instruction. In addition, the sample, based on opportunity and snowballing sampling methods, was predominantly white and generally of a similar socio-economic class. These results can therefore only be interpreted within these constraints. Social support in particular may be very different in different groups [53], as will be opportunities for exercise.

Overall, the results of this have shown that when mothers are free to choose how they engage in physical activity (i.e., not part of an intervention), those who choose, and are able, to engage in mother-baby classes are at a lower risk for depression and have better social support than those who exercise alone or not at all. This suggests that mother-baby exercise classes, rather than solitary exercise, should be promoted, particularly when considering the push to improve post-partum women's low levels of physical activity [54,55]. Tackling the logistical barriers that preclude mothers from attending group post-partum exercise should be a priority.

\section{References}

1. Leahy-Warren P, McCarthy G, Corcoran P (2012) Firsttime mothers: Social support, maternal parental self-efficacy and postnatal depression. J Clin Nurs 21: 388-397.

2. Sander J, Schupp J, Richter D (2017) Getting together: Social contact frequency across the life span. Dev Psychol 53: 1571-1588.

3. Corrigan CP, Kwasky AN, Groh CJ (2015) Social support, postpartum depression, and professional assistance: A survey of mothers in the Midwestern United States. J Perinat Educ 24: 48-60.

4. Harwood K, McLean N, Durkin K (2007) First-time mothers' expectations of parenthood: What happens when optimistic expectations are not matched by later experiences? Dev Psychol 43: 1-12.

5. Weiner CL, Primeau M, Ehrmann DA (2004) Androgens and mood dysfunction in women: Comparison of women with polycystic ovarian syndrome to healthy controls. Psychosom Med 66: 356-362.

6. Roomruangwong C, Kanchanatawan B, Sirivichayakul S, et al. (2017) High incidence of body image dissatisfaction in pregnancy and the postnatal period: Associations with depression, anxiety, body mass index and weight gain during pregnancy. Sex Reprod Healthc 13: 103-109.

7. Hodgkinson EL, Smith DM, Wittkowski A (2014) Women's experiences of their pregnancy and postpartum body image: A systematic review and meta-synthesis. BMC Pregnancy Childbirth 14: 1-11.

8. Schalla SC, Witcomb G, Haycraft E (2017) Body shape and weight loss as motivators for breastfeeding initiation and continuation. Int J Envir Res Pub Health 14.

9. Parry DC, Glover TD, Mulcahy CM (2013) From 'stroller-stalker' to 'momancer': Courting friends through a social networking site for mothers. Journal of Leisure Research 45: 23-46.
10. Grigoriadis S, Ravitz P (2007) An approach to interpersonal psychotherapy for postpartum depression: Focusing on interpersonal changes. Can Fam Physician 53: 1469-1475.

11. Philpott LF, Corcoran P (2018) Paternal postnatal depression in Ireland: Prevalence and associated factors. Midwifery 56: 121-127.

12. Field T (2010) Postpartum depression effects on early interactions, parenting, and safety practices: A review. Infant Behav Dev 33: 1-6.

13. McLearn KT, Minkovitz CS, Strobino DM, et al. (2006) The timing of maternal depressive symptoms and mothers' parenting practices with young children: Implications for pediatric practice. Pediatrics 118: e174-e182.

14. Nesti E, Pearson RM, Murray L, et al. (2018) Association of persistent and severe postnatal depression with child outcomes. JAMA Psychiatry 75: 247-253.

15. Mickelson KD, Biehle SN, Chong A, et al. (2017) Perceived stigma of postpartum depression symptoms in low-risk firsttime parents: Gender differences in a dual-pathway model. Sex Roles 76: 306-318.

16. Cipriani A, Furukawa TA, Salanti G, et al. (2018) Comparative efficacy and acceptability of 21 antidepressant drugs for the acute treatment of adults with major depressive disorder: A systematic review and network meta-analysis. Lancet 391: 1357-1366.

17. Shulman B, Dueck R, Ryan D, et al. (2018) Feasibility of a mindfulness-based cognitive therapy group intervention as an adjunctive treatment for postpartum depression and anxiety. J Affect Dis 235: 61-67.

18. Umylny P, German M, Lantiere A (2017) Treating post-partum mood and anxiety disorders in primary care paediatrics. Curr Probl Paediatr Adolesc Health Care 47: 254-266.

19. Milgrom J, Gemmill AW, Ericksen J, et al. (2015) Treatment of postnatal depression with cognitive behavioural therapy, sertraline and combination therapy: A randomised controlled trial. Aust N Z Y Psychiatry 49: 236-245.

20. Weissman AM, Levy BT, Hartz AJ, et al. (2004) Pooled analysis of antidepressant levels in lactating mothers, breast milk, and nursing infants. Am J Psychiatry 161: 1066-1078.

21. van Zoonen K, Buntrock C, Ebert DD, et al. (2014) Preventing the onset of major depressive disorder: A meta-analytic review of psychological interventions. Int J Epidemiol 43: 318-329.

22. Molyneaux E, Telesia LA, Henshaw C, et al. (2018) Antidepressants for preventing postnatal depression. Cochrane Database of Syst Rev.

23. Miller LJ, LaRusso EM (2011) Preventing postpartum depression. Psychiatr Clin North Am 34: 53-65.

24. Armstrong K, Edwards $\mathrm{H}$ (2004) The effectiveness of a pram-walking exercise programme in reducing depressive symptomatology for postnatal women. Int J Nurs Pract 10: 177-194.

25. Hancock KJ, Cunningham NK, Lawrence D, et al. (2015) Playgroup participation and social support outcomes for mothers of young children: A longitudinal cohort study. PLoS One 10: 1-15.

26. Reid KM, Taylor MG (2015) Social support, stress, and maternal postpartum depression: A comparison of supportive relationships. Soc Sci Res 54: 246-262. 
Citation: Witcomb GL, Harding Z (2018) An Exercise in Happiness: Physical Activity Choices and Psychological Wellbeing in Post-Partum Mothers. Arch Sports Med 2(2):109-115

27. Buist A, Bilszta J, Barnett B, et al. (2005) Recognition and management of perinatal depression in general practice--a survey of GPs and postnatal women. Aust Fam Physician 34: 787-790.

28. Davis K, Dimidjian S (2012) The relationship between physical activity and mood across the perinatal period: A review of naturalistic and clinical research to guide future investigation of physical activity-based interventions for perinatal depression. Clin Psychol-Sci Pr 19: 27-48.

29. Harvey SB, Øverland S, Hatch SL, et al. (2017) Exercise and the prevention of depression: Results of the HUNT cohort study. Am J Psychiatry 175: 28-36.

30. Meyer JD, Koltyn KF, Stegner AJ, et al. (2016) Influence of exercise intensity for improving depressed mood in depression: A dose-response study. Behav Ther 47: 527-537.

31. Schuch FB, Vancampfort D, Richards J, et al. (2016) Exercise as a treatment for depression: A meta-analysis adjusting for publication bias. J Psychiatr Res 77: 42-51.

32. Lovell GP, Huntsman A, Hedley-Ward J (2015) Psychological distress, depression, anxiety, stress, and exercise in Australian and New Zealand mothers: A cross-sectional survey. Nurs Health Sci 17: 42-48.

33. Brown WJ, Mishra G, Lee C, et al. (2000) Leisure time physical activity in Australian women: Relationship with well-being and symptoms. Res Q Exerc Sport 71: 206-216.

34. Albright CL, Maddock JE, Nigg CR (2006) Physical activity before pregnancy and following childbirth in a multiethnic sample of healthy women in Hawaii. Women Health 42: 95-110.

35. Currie JL, Develin E (2002) Stroll your way to well-being: A survey of the perceived benefits, barriers, community support, and stigma associated with pram walking groups designed for new mothers, Sydney, Australia. Health Care Women Int 23: 882-893.

36. Ansari WE, Lovell G (2009) Barriers to exercise in younger and older non-exercising adult women: A cross sectional study in London, United Kingdom. Int J Environ Res Pub Health 6: 1443-1455.

37. Mailey E, Huberty J, Dinkel D, et al. (2014) Physical activity barriers and facilitators among working mothers and fathers. BMC Public Health 14: 657.

38. Smith G, Banting L, Eime R, et al. (2017) The association between social support and physical activity in older adults: A systematic review. Int J Behav Nutr Physical Act 14: 1-21.

39. Armstrong K, Edwards $\mathrm{H}$ (2003) The effects of exercise and social support on mothers reporting depressive symptoms: A pilot randomized controlled trial. Int $\mathrm{J}$ Ment Health Nurs 12: $130-138$.

40. Mclnnes RJ, Dickson C, Barclay C (2017) Buggy walking groups: An asset-based approach to health care. J Health Visit 5: 236-243.
41. Brown AM, Robinson A, Jones F (2017) The effectiveness of prescription exercises for women diagnosed with postnatal depression: A systematic review. MIDIRS Midwifery Digest 27: 488-495.

42. Blamey RV, Daley AJ, Jolly K (2012) Exercise for postnatal psychological outcomes: A systematic review and meta-analysis. Lancet 380: S25.

43. Norman E, Sherburn M, Osborne RH, et al. (2010) An exercise and education program improves well-being of new mothers: A randomized controlled trial. Phys Ther 90: 348-355.

44. Cox JL, Holden JM, Sagovsky R (1987) Detection of postnatal depression: Development of the 10-item Edinburgh Postnatal Depression Scale. Br J Psychiatry 150: 782-786.

45. Zimet GD, Dahlem NW, Zimet SG, et al. (1988) The Multidimensional Scale of Perceived Social Support. J Pers Assess 52: 30-41.

46. Brown SL, Nesse RM, Vinokur AD, et al. (2003) Providing social support may be more beneficial than receiving it: $\mathrm{Re}-$ sults from a prospective study of mortality. Psychol Sci 14: 320-327.

47. Homan KJ, Tylka TL (2014) Appearance-based exercise motivation moderates the relationship between exercise frequency and positive body image. Body Image 11: 101-108.

48. Lawlor DA, Hopker SW (2001) The effectiveness of exercise as an intervention in the management of depression: Systematic review and meta-regression analysis of randomized controlled trials. BMJ 322: 1-8.

49. Hartley E, Hill B, McPhie S, et al. (2018) The associations between depressive and anxiety symptoms, body image, and weight in the first year postpartum: A rapid systematic review. J Reprod infant Psychol 36: 81-101.

50. Lovering ME, Rodgers RF, George JE, et al. (2018) Exploring the tripartite influence model of body dissatisfaction in postpartum women. Body Image 24: 44-54.

51. Stanton R, Reaburn $P$ (2014) Exercise and the treatment of depression: A review of the exercise program variables. $J$ Sci Med Sport 17: 177-182.

52. Thoits PA (2011) Mechanisms linking social ties and support to physical and mental health. J Health Soc Behav 52: 145-161.

53. Feeney BC, Collins NL (2015) A new look at social support: A theoretical perspective on thriving through relationships. Pers Soc Psychol Rev 19: 113-147.

54. Hopkinson Y, Hill DM, Fellows L, et al. (2018) Midwives understanding of physical activity guidelines during pregnancy. Midwifery 59: 23-26.

55. McCurdy AP, Boulé NG, Siva A, et al. (2017) Effects of exercise on mild-to-moderate depressive symptoms in the postpartum period: A meta-analysis. Obstet Gynecol 129: 1087-1097. 